Article

\title{
Synthesis Characterization and Photocatalytic Studies of Cobalt Ferrite-Silica-Titania Nanocomposites
}

\author{
David Greene ${ }^{1}$, Raquel Serrano-Garcia ${ }^{1}$, Joseph Govan ${ }^{1}$ and Yurii K. Gun'ko ${ }^{1,2, *}$ \\ 1 School of Chemistry and CRANN, Trinity College Dublin, Dublin 2, Ireland; \\ E-Mails: greenedj@tcd.ie (D.G.); serranr@tcd.ie (R.S.-G.); govanj@tcd.ie (J.G.) \\ 2 St. Petersburg National Research University of Information Technologies, Mechanics and Optics, \\ St. Petersburg 197101, Russia \\ * Author to whom correspondence should be addressed; E-Mail: igounko@tcd.ie; \\ Tel.: +353-1-896-35-43.
}

Received: 23 February 2014; in revised form: 11 April 2014 / Accepted: 11 April 2014 / Published: 23 April 2014

\begin{abstract}
In this work, $\mathrm{CoFe}_{2} \mathrm{O}_{4} @ \mathrm{SiO}_{2} @ \mathrm{TiO}_{2}$ core-shell magnetic nanostructures have been prepared by coating of cobalt ferrite nanoparticles with the double $\mathrm{SiO}_{2} / \mathrm{TiO}_{2}$ layer using metallorganic precursors. The Transmission Electron Microscopy (TEM), Energy Dispersive X-Ray Analysis (EDX), Vibrational Sample Magnetometer (VSM) measurements and Raman spectroscopy results confirm the presence both of the silica and very thin $\mathrm{TiO}_{2}$ layers. The core-shell nanoparticles have been sintered at $600{ }^{\circ} \mathrm{C}$ and used as a catalyst in photo-oxidation reactions of methylene blue under UV light. Despite the additional non-magnetic coatings result in a lower value of the magnetic moment, the particles can still easily be retrieved from reaction mixtures by magnetic separation. This retention of magnetism was of particular importance allowing magnetic recovery and re-use of the catalyst.
\end{abstract}

Keywords: magnetic nanoparticles; core-shell; silica; titanium dioxide; photocatalysis; magnetic separation

\section{Introduction}

Core-shell multifunctional magnetic nanoparticles have a wide variety of applications including catalysis, magnetic separation and numerous biomedical uses. There are many approaches of coating of 
magnetic nanoparticles with various coatings including noble metal, carbon, silica, zirconia, titania and polymer shells [1-4]. Silica coated-iron magnetic oxide based nanocomposites have attracted particular interest as the silica coating on magnetic nanoparticles gives a number of advantages. It was demonstrated that $\mathrm{SiO}_{2}$ coating can protect the nanostructure against degradation and oxidation of the magnetic core (e.g., $\mathrm{Fe}_{3} \mathrm{O}_{4}$ or $\mathrm{Fe}$ ) [5]. For example, it was shown that a silica coating on $\gamma-\mathrm{Fe}_{2} \mathrm{O}_{3}$ can prevent the thermal transition of $\gamma-\mathrm{Fe}_{2} \mathrm{O}_{3}$ to the less magnetic $\alpha-\mathrm{Fe}_{2} \mathrm{O}_{3}$ [6]. As a result the silica-coated magnetic nanoparticles are stable against degradation which improves their biocompatibility and facilitates their utilization. Furthermore, the ease of silica surface modification [7] allows for further specific functionalization to perform catalysis, biolabeling and drug delivery [5,8-14]. The surface of silica has also been shown to be easily modified with cationic groups which can improve its electrostatic binding to DNA [15] enhancing its use as a drug delivery agent and improving its cellular transport.

Titanium dioxide is another very important material which has also been applied for the coating and functionalization of magnetic nanoparticles [16-18]. Titanium dioxide has been used for many years as a white pigment in paint, sunscreen and even toothpaste [19,20]. $\mathrm{TiO}_{2}$ nanoparticles have also found important applications in photovoltaic cells (e.g., dye sensitized solar cells), gas sensing, photo-electrodes and as efficient photocatalysts [20,21]. The photo-catalytic trait of $\mathrm{TiO}_{2}$ arises from the electron-hole pair that forms upon irradiation of $\mathrm{TiO}_{2}$ under UV light. The resultant charge carriers that are formed can then migrate to the surface of the particle where they can react with adsorbed water and oxygen to form oxidative radical species such as peroxide radicals. These radicals can then oxidize organic molecules present at the surface [22]. The ability of $\mathrm{TiO}_{2}$ to photo-catalyze the degradation of organic compounds has been exploited in environmental sectors to reduce the levels of organic contaminants in polluted water and polluted air as well as in self-cleaning windows and surfaces $[20,23]$. $\mathrm{TiO}_{2}$ can exist in three crystalline phases, anatase, rutile and brookite. Of these phases the anatase phase displays the highest photo-catalytic activity [24,25]. This phase can normally be produced by heating $\mathrm{TiO}_{2}$ particles, between 400 and $600{ }^{\circ} \mathrm{C}$ [21].

The main aim of this work is to prepare and investigate cobalt ferrite based nanoparticles which are coated by a double silica/titania shell. It is expected that the introduction of the $\mathrm{SiO}_{2}$ coat between the ferrite and the $\mathrm{TiO}_{2}$ shell should reduce the recombination processes between the titania shell and ferrite core as the $\mathrm{SiO}_{2}$ could act as an insulator against electron donation [26]. We have selected cobalt ferrite as a magnetic core material because it is more thermally robust and stable comparing to magnetic iron oxide and therefore cobalt ferrite should be suitable for the further preparation of multi-shell structures and a potential thermal treatment at high temperatures. Another goal of our work is to test these new $\mathrm{CoFe}_{2} \mathrm{O}_{4} @ \mathrm{SiO}_{2} @ \mathrm{TiO}_{2}$ core-shell magnetic nanostructures as catalysts for the photo-oxidation of methylene blue dye, under UV light and evaluate their potential as magnetically retrievable and re-usable photo-catalysts.

\section{Results and Discussion}

\subsection{Synthesis and Characterization of $\mathrm{CoFe}_{2} \mathrm{O}_{4}$ Nanoparticles}

Cobalt ferrite nanoparticles were synthesized by the co-precipitation of cobalt(II) nitrate and iron(III) chloride in the presence of ammonium hydroxide according to a previously reported procedure [27]. 
The product was a dark brown/black solid. The magnetic moment of the $\mathrm{CoFe}_{2} \mathrm{O}_{4}$ sample was $85.65 \mathrm{~A} \cdot \mathrm{m}^{2} \cdot \mathrm{kg}^{-1}$. The Transmission Electron Microscopy (TEM) imaging (Figure 1) have shown the $\mathrm{CoFe}_{2} \mathrm{O}_{4}$ nanoparticles with the size distribution between 40 and $100 \mathrm{~nm}$.

The X-ray powder diffraction (XRD) pattern below also confirmed the formation of the $\mathrm{CoFe}_{2} \mathrm{O}_{4}$ phase (Figure 2). The peaks in the diffractogram were in agreement with the expected sample peaks for cobalt ferrite as given in the JCPDS database and relevant literature [28].

Figure 1. Transmission Electron Microscopy (TEM) image of uncoated $\mathrm{CoFe}_{2} \mathrm{O}_{4}$ nanoparticles.

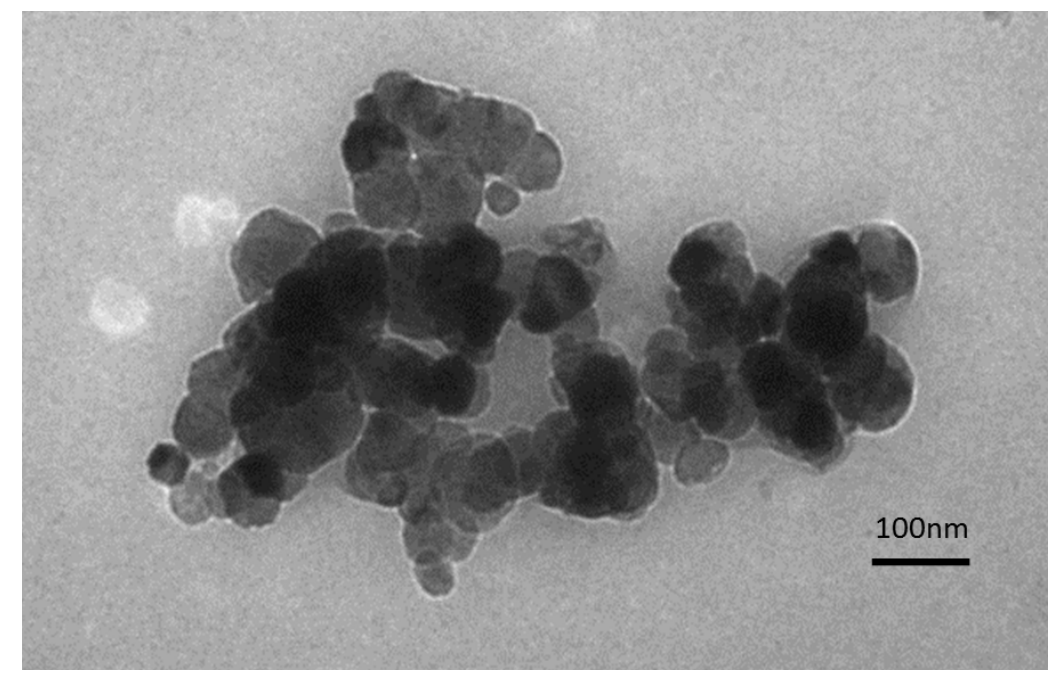

Figure 2. X-ray powder diffraction (XRD) pattern of initial $\mathrm{CoFe}_{2} \mathrm{O}_{4}$ nanoparticles.

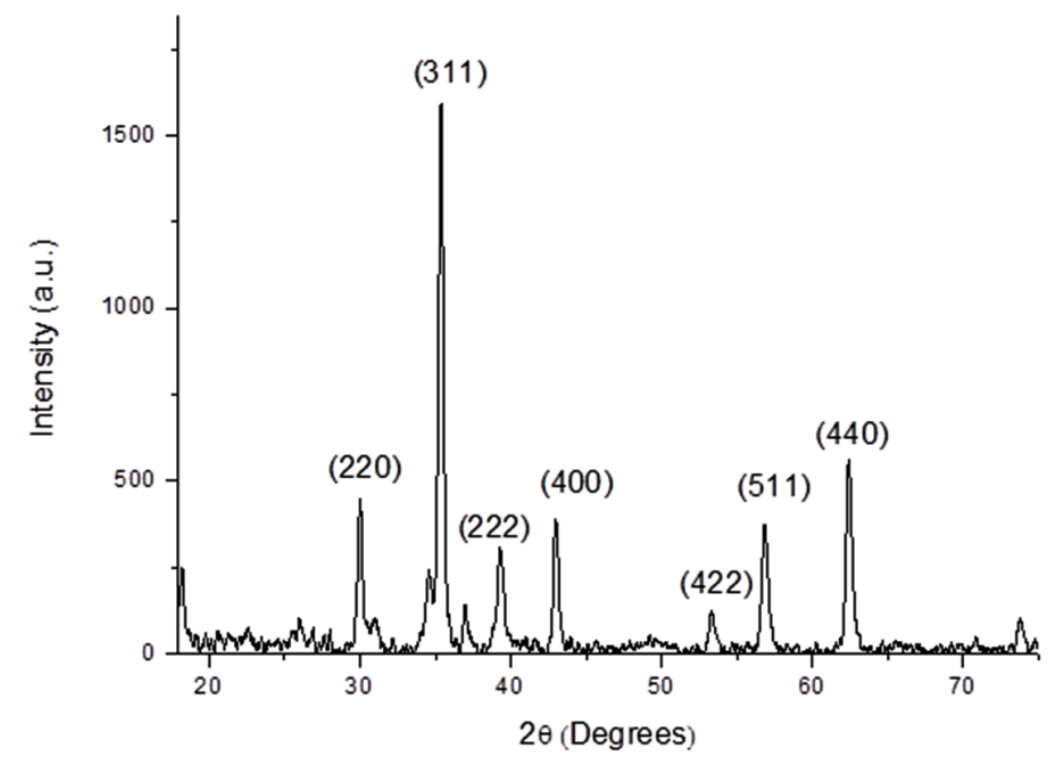

\subsection{Synthesis and Characterization of $\mathrm{CoFe}_{2} \mathrm{O}_{4} / \mathrm{SiO}_{2}$ Core-Shell Nanostructures}

Silica coating of the cobalt ferrite nanoparticles was produced using tetraethylorthosilicate (TEOS) and ammonia solution. According to magnetization studies, the magnetic moment of the silica coated cobalt ferrite sample was reduced to $15.99 \mathrm{~A} \cdot \mathrm{m}^{2} \cdot \mathrm{kg}^{-1}$. This drop in magnetic moment was due to the presence of non-magnetic $\mathrm{SiO}_{2}$ coating. This is a significant descent which enables us to suggest that the coating is quite thick. This was confirmed by the TEM data below (Figure 3 ). 
The TEM images (Figure 3) showed a core-shell structure of the nanoparticles, although a large amount of aggregation is observed: the particles sticking together to form clumps and aggregates of particles which are then coated with the $\mathrm{SiO}_{2}$. According to TEM, the particles range in size from approximately $40 \mathrm{~nm}$ up to $100 \mathrm{~nm}$ in the core, with the coatings being approximately $50 \mathrm{~nm}$ in thickness. This gives the particles a total size of between 90 and $150 \mathrm{~nm}$. Although these images do not show the ideal structure of a single core contained within a shell, they do confirm the formation of the required core-shell silica-cobalt ferrite nanoparticles.

The XRD pattern for $\mathrm{SiO}_{2}$ coated $\mathrm{CoFe}_{2} \mathrm{O}_{4}$ nanoparticlesis is shown in Figure 4. Again the dominating peaks present are those of $\mathrm{CoFe}_{2} \mathrm{O}_{4}$ as discussed above. The broad peak at low angles may indicate the presence of the amorphous $\mathrm{SiO}_{2}$. By comparison with the JCPDS database for $\mathrm{SiO}_{2}$ and the results obtained by $\mathrm{Hu}$ et al. [29], the peak at 31 contain a trace of $\mathrm{SiO}_{2}$ along with the peak at $2 \theta \approx 35$, however both of these peaks are highly masked by the $\mathrm{CoFe}_{2} \mathrm{O}_{4}$ peaks in the same area.

Figure 3. TEM images of the $\mathrm{SiO}_{2}$ coated $\mathrm{CoFe}_{2} \mathrm{O}_{4}$ nanoparticles.
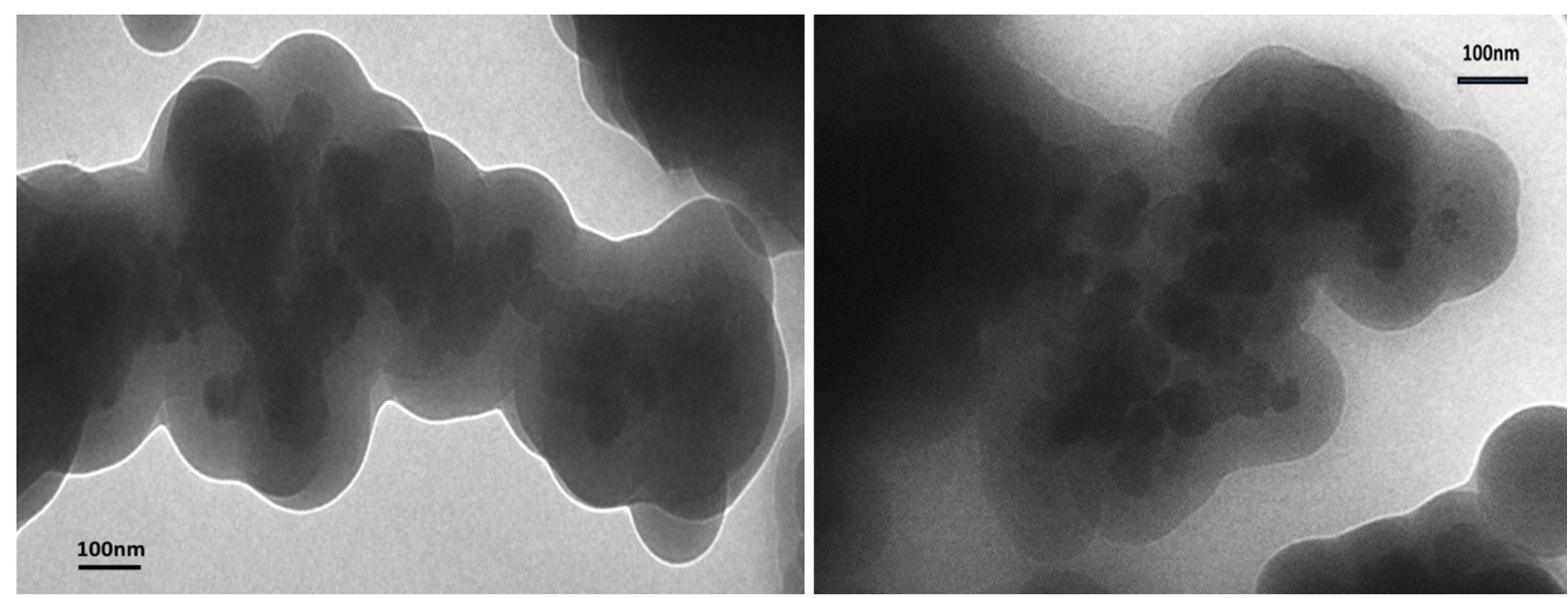

Figure 4. $\mathrm{XRD}$ pattern of $\mathrm{SiO}_{2}$ coated $\mathrm{CoFe}_{2} \mathrm{O}_{4}$ nanoparticles before and after sintering at $600{ }^{\circ} \mathrm{C}$.

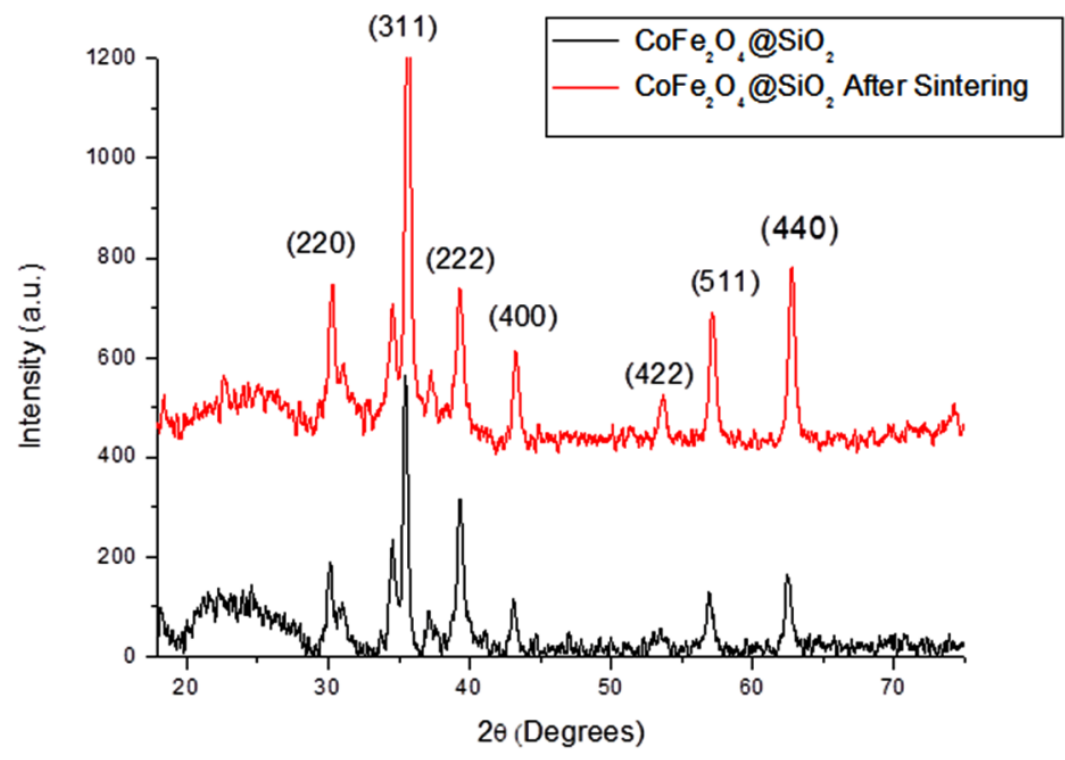




\subsection{Synthesis and Characterization of $\mathrm{CoFe}_{2} \mathrm{O}_{4} @ \mathrm{SiO}_{2} @ \mathrm{TiO}_{2}$ Core-Shell Nanostructures}

Titania/silica coated cobalt ferrite nanoparticles have been prepared by hydrolysis of titanium tetrabutoxide precursor in the presence of silica coated cobalt ferrite nanoparticles according to the scheme below (Figure 5).

Figure 5. Reaction scheme for the coating of $\mathrm{SiO}_{2}$ coated cobalt ferrite nanoparticles with a second $\mathrm{TiO}_{2}$ coating.
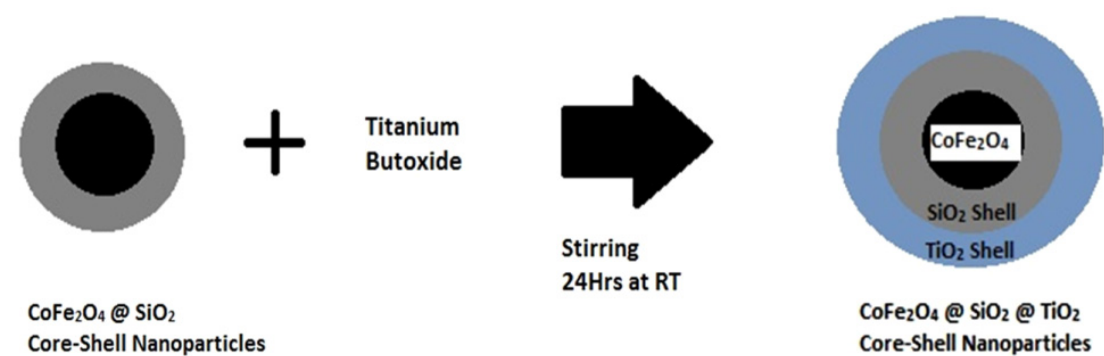

After applying the silica/titania double coating, the magnetic moment of the sample dropped again to $12.46 \mathrm{~A} \cdot \mathrm{m}^{2} \cdot \mathrm{kg}^{-1}$ (Figure 6). This reduction in magnetic moment proves that the size of the non-magnetic coating has increased due to the presence of non-magnetic $\mathrm{TiO}_{2}$ shell, resulting in a lower magnetic moment. As the drop in magnetic moment is very low this time, it would indicate that the $\mathrm{TiO}_{2}$ coating is very thin in comparison with the $\mathrm{SiO}_{2}$ coating. This was also confirmed by TEM results.

Figure 6. Vibrational Sample Magnetometer (VSM) curves of $\mathrm{CoFe}_{2} \mathrm{O}_{4}, \mathrm{CoFe}_{2} \mathrm{O}_{4} @ \mathrm{SiO}_{2}$ and $\mathrm{CoFe}_{2} \mathrm{O}_{4} @ \mathrm{SiO}_{2} @ \mathrm{TiO}_{2}$ coated nanostructures.

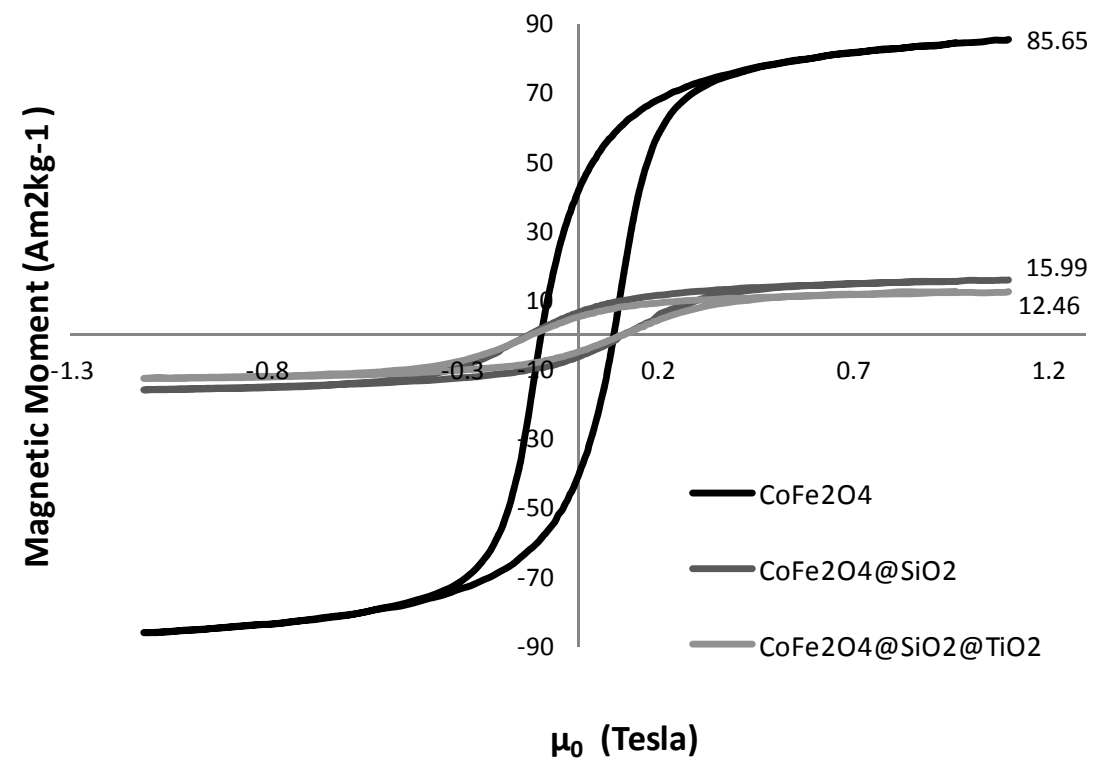

TEM images of the double coated sample of $\mathrm{CoFe}_{2} \mathrm{O}_{4}$ are shown in Figure 7. In the TEM images we can clearly see the presence of two types of coating on the $\mathrm{CoFe}_{2} \mathrm{O}_{4}$ nanoparticles. The main coating around the core is a $\mathrm{SiO}_{2}$ shell of approximately $50 \mathrm{~nm}$ thick. Then the second $\mathrm{TiO}_{2}$ coating lies on top of the silica shell. However, the $\mathrm{TiO}_{2}$ does not form a complete solid coating on the $\mathrm{SiO}_{2}$ but rather some 
isolated fragments of $\mathrm{TiO}_{2}$. Most likely the complete uniform titania coating does not form in this case due to a lattice mismatch between $\mathrm{SiO}_{2}$ and $\mathrm{TiO}_{2}$.

The Energy Dispersive X-ray (EDX) analysis of the samples (Figure 8) confirms the presence of elements corresponding to $\mathrm{CoFe}_{2} \mathrm{O}_{4}, \mathrm{SiO}_{2}$ and $\mathrm{TiO}_{2}$ further proving the formation of a double coating.

Figure 7. TEM images of the two types of coating around the $\mathrm{CoFe}_{2} \mathrm{O}_{4}$ core, forming the double coated core-shell nanostructures.
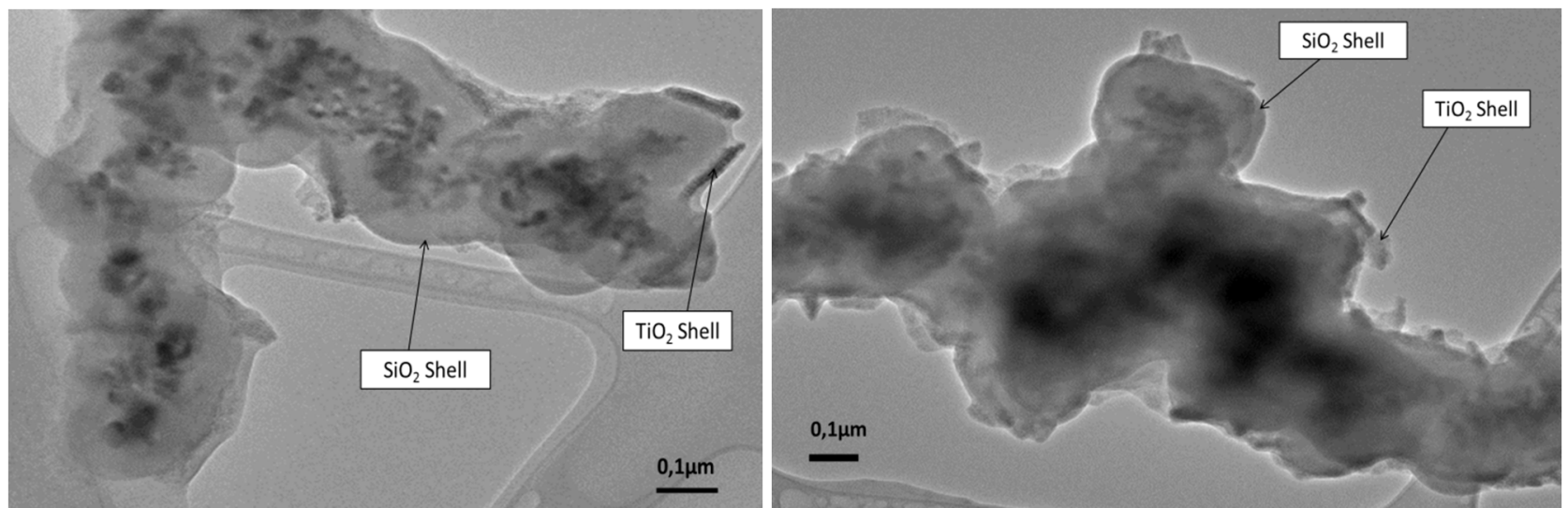

Figure 8. Energy Dispersive $\mathrm{X}$-Ray (EDX) analysis of the $\mathrm{TiO}_{2} / \mathrm{SiO}_{2}$ coated $\mathrm{CoFe}_{2} \mathrm{O}_{4}$ nanostructures.
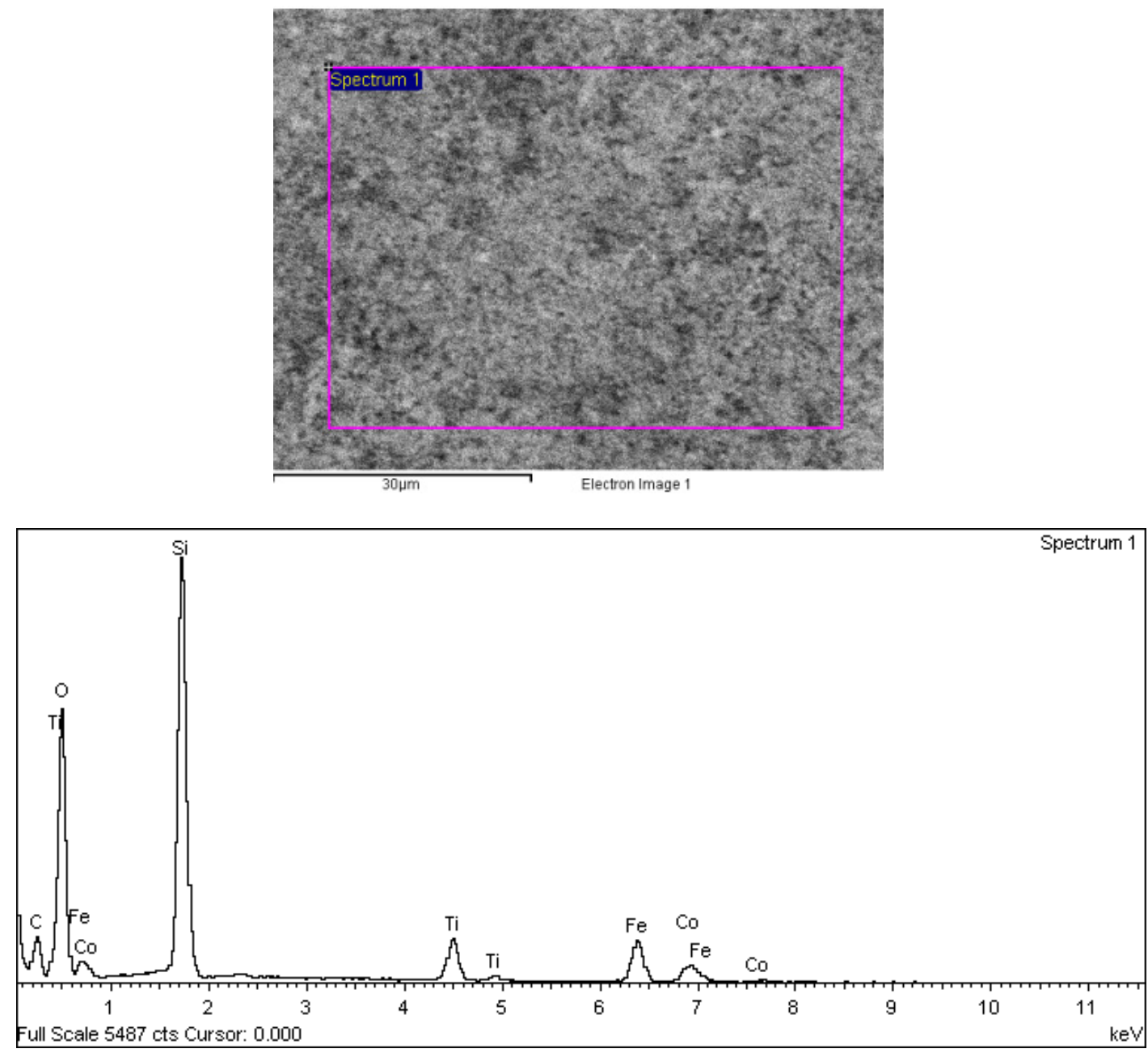
The presence of thermally stable cobalt ferrite core enabled us to perform sintering of the $\mathrm{CoFe}_{2} \mathrm{O}_{4} @ \mathrm{SiO}_{2} @ \mathrm{TiO}_{2}$ core-shell nanostructures at $600{ }^{\circ} \mathrm{C}$ in order to produce photocatalytically active anatase and rutile forms of $\mathrm{TiO}_{2}$. Figure 9 displays the Raman spectra of $\mathrm{TiO}_{2} / \mathrm{SiO}_{2}$ coated $\mathrm{CoFe}_{2} \mathrm{O}_{4}$ nanoparticles which were sintered at $600{ }^{\circ} \mathrm{C}$ for $1 \mathrm{~h}$. The sharp peak at $146 \mathrm{~cm}^{-1}$ is indicative of the presence of $\mathrm{TiO}_{2}$ in the anatase phase. Although the rutile phase also exhibits a peak around this area it is a normally very weak signal, therefore this peak is due to the presence of the anatase phase [30]. However the peaks at $450 \mathrm{~cm}^{-1}$ and $614 \mathrm{~cm}^{-1}$ would suggest the presence of $\mathrm{TiO}_{2}$ in the rutile phase [31]. This has most likely arisen due to the heat treatment of the nanoparticles. Some of the $\mathrm{TiO}_{2}$ present may have converted from the amorphous phase to the anatase phase while some may have converted further to the rutile phase resulting in a mixture of $\mathrm{TiO}_{2}$ phases on the nanoparticle surface. The peaks at $460 \mathrm{~cm}^{-1}$ and $680 \mathrm{~cm}^{-1}$ indicate the presence of cobalt ferrite. The $\mathrm{SiO}_{2}$ peaks are also quite weak and hard to distinguish in this spectrum however the broad peak centered at $300 \mathrm{~cm}^{-1}$ in the spectrum indicates the presence of a $\mathrm{SiO}_{2}$ shell.

Figure 9. Raman spectrum of $\mathrm{CoFe}_{2} \mathrm{O}_{4} @ \mathrm{SiO}_{2} @ \mathrm{TiO}_{2}$ core-shell nanostructures.

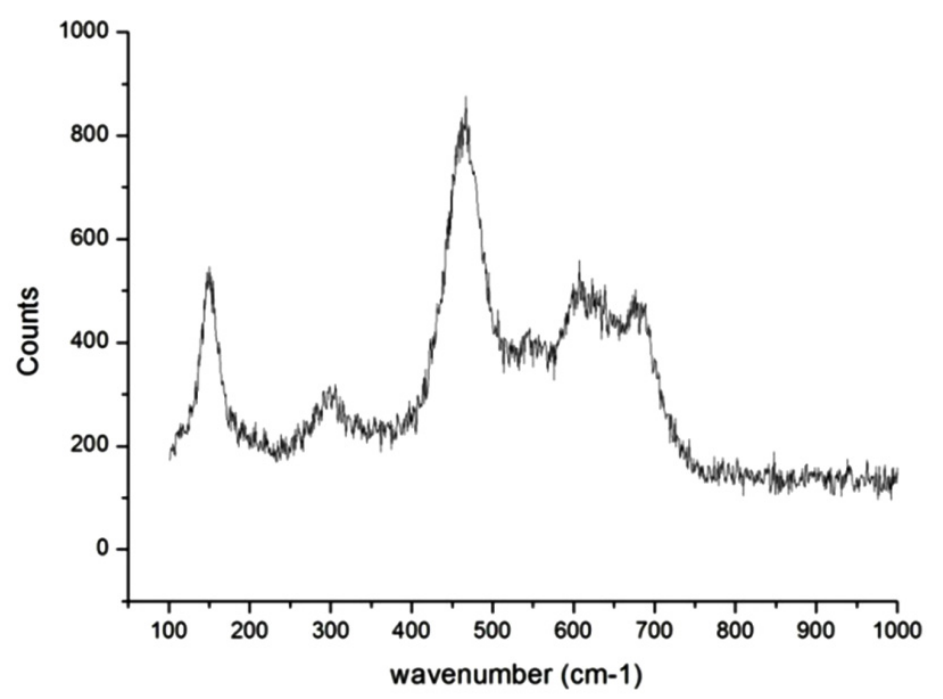

\subsection{Photocatalytic Activity Testing of $\mathrm{CoFe}_{2} \mathrm{O}_{4} @ \mathrm{SiO}_{2} @ \mathrm{TiO}_{2}$ Core-Shell Nanoparticles}

The $\mathrm{CoFe}_{2} \mathrm{O}_{4} @ \mathrm{SiO}_{2} @ \mathrm{TiO}_{2}$ core-shell nanoparticles sintered at $600{ }^{\circ} \mathrm{C}$ were used for photo-catalytic testing. After these nanoparticles were added to the methylene blue solution, the absorbance of the dye reduced much faster as opposed to the control tests. This is a clear indication of photo-catalytic activity of these samples. The Figure 10 (top left) displays the decrease in absorbance of the methylene blue dye over time in the presence of the sintered $\mathrm{CoFe}_{2} \mathrm{O}_{4} / \mathrm{SiO}_{2} / \mathrm{TiO}_{2}$ nanoparticles under UV illumination versus that with no nanoparticles present (Figure 10, top right), in the presence of $\mathrm{CoFe}_{2} \mathrm{O}_{4} @ \mathrm{SiO}_{2}$ nanoparticles (bottom left) and $\mathrm{CoFe}_{2} \mathrm{O}_{4} @ \mathrm{SiO}_{2} @ \mathrm{TiO}_{2}$ without UV illumination all as controls (bottom right). As shown, the rate of decrease in absorbance is much higher than that of the control samples. This shows that the $\mathrm{TiO}_{2}$ coating is catalyzing the photo-oxidation of the dye molecules as expected. The slight decrease in absorption in the control tests is most likely due to partial bleaching of dye molecules under the UV-light or the absorbance of dye molecules to the surface of the catalyst species in the case of the dark (no UV illumination) control. 
Figure 10. Graphs showing the absorption of methylene blue dye with the catalytic $\mathrm{CoFe}_{2} \mathrm{O}_{4} @ \mathrm{SiO}_{2} @ \mathrm{TiO}_{2}$ nanoparticles present over time (Top Left) for catalytic testing and also showing just the dye without the nanoparticles present (Top Right), the dye in the presence of $\mathrm{CoFe}_{2} \mathrm{O}_{4} @ \mathrm{SiO}_{2}$ nanoparticles (Bottom Left) and in the presence of $\mathrm{CoFe}_{2} \mathrm{O}_{4} @ \mathrm{SiO}_{2} @ \mathrm{TiO}_{2}$ without UV illumination (Bottom Right) all as controls.
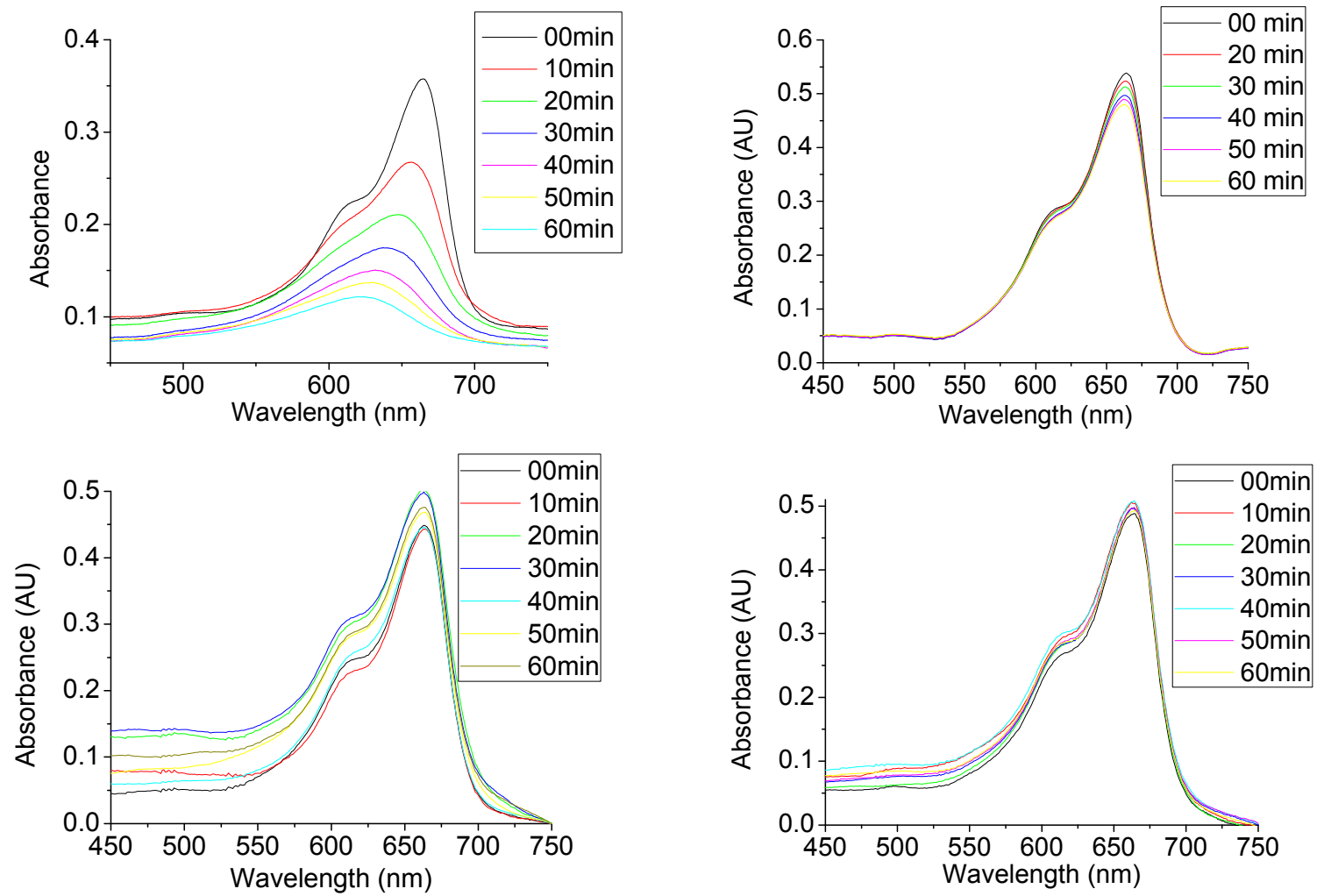

Figure 11 (Left) shows the changes in the maximum of dye absorbance plotted against time for the reaction of the $\mathrm{CoFe}_{2} \mathrm{O}_{4} @ \mathrm{SiO}_{2} @ \mathrm{TiO}_{2}$ catalyst sintered at $600{ }^{\circ} \mathrm{C}$. In the control tests it is observed that the absorbance drops linearly with increasing time. This shows that the bleaching of the dye under UV light is a linear reaction and is independent of the concentration of methylene blue. When the core-shell nanoparticles are added as a catalyst it is clear that we have the first order reaction here according to the plot of the Log (1/Max Abs) versus time (Figure 11, Right). This is in line with previous reports on $\mathrm{TiO}_{2}$ nanoparticle based photocatalytic species [18,20,25,32].

Finally, it is very important to notice that the $\mathrm{CoFe}_{2} \mathrm{O}_{4} @ \mathrm{SiO}_{2} @ \mathrm{TiO}_{2}$ nanoparticles of the catalyst were totally recoverable from the reaction mixture using a simple magnetic separation using a permanent magnet as demonstrated in Figure 12. 
Figure 11. Graph of the changes in the maximum of dye absorbance plotted against time for catalytic $\mathrm{CoFe}_{2} \mathrm{O}_{4} @ \mathrm{SiO}_{2} @ \mathrm{TiO}_{2}$ nanoparticles sintered at $600{ }^{\circ} \mathrm{C}$ (Left). Graph of Log (1/Max Abs) versus time for the catalytic $\mathrm{CoFe}_{2} \mathrm{O}_{4} @ \mathrm{SiO}_{2} @ \mathrm{TiO}_{2}$ nanoparticles sintered at $600{ }^{\circ} \mathrm{C}$ (Right).
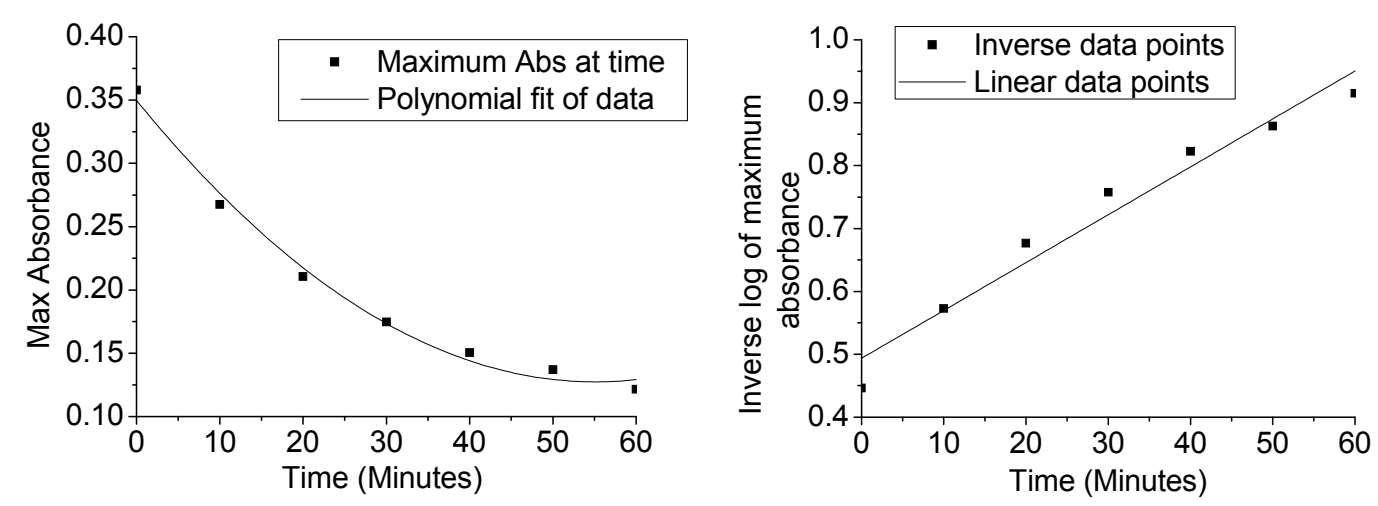

Figure 12. Images of suspended $\mathrm{CoFe}_{2} \mathrm{O}_{4} @ \mathrm{SiO}_{2} @ \mathrm{TiO}_{2}$ in methylene blue solution in water (Left) and in the presence of a permanent magnet (Right).
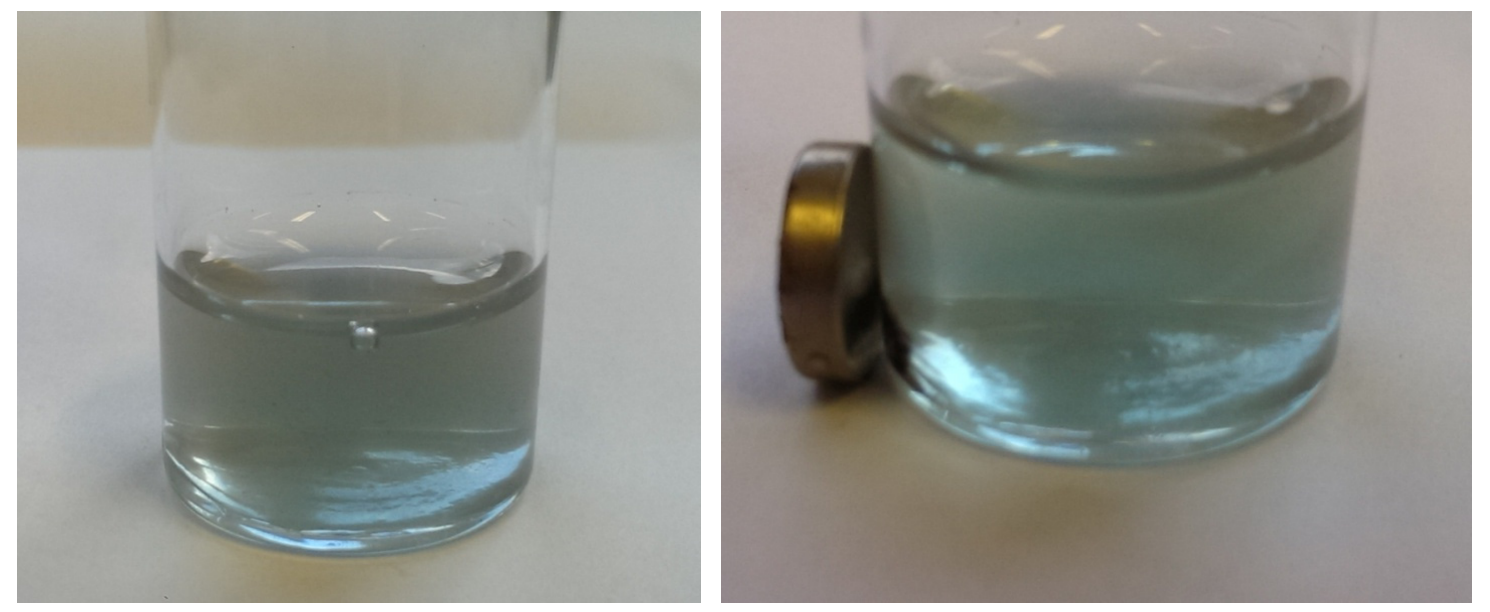

\section{Experimental Section}

\subsection{General Procedures}

All chemicals were purchased from Sigma-Aldrich and used as supplied unless stated otherwise. Solvents were obtained from the solvent stores at TCD and again were used as received unless stated.

All sonication processing was carried out using either Branson 2510 sonic bath or a Grant Scientific sonic bath operating at $60 \mathrm{~Hz}$. Every magnetic separation was carried out using a 0.5 Tesla magnet.

All TEM imaging and EDX analysis were carried out on a FEI Titan Themis 200 series machine (FEI, Hillsboro, OR, USA).

Raman spectra were recorded using Raman microscope (Renishaw, Gloucestershire, UK) operating at $785 \mathrm{~nm}$ using $1 \%$ of the $200 \mathrm{~mW}$ power.

X-ray diffraction was performed using Siemens-500 X-ray diffractometer (Siemens, Munich, Germany), Cu metal $1.5406 \AA$. Powder samples were deposited on silica glass using grease to adhere 
the sample to the glass surface. Overnight patterns were run for all samples. Diffractograms were then compared to the JCPDS database.

Magnetisation measurements were carried out using a custom made permanent magnet variable flux source vibrating sample magnetometer (VSM; home-build, School of Physics, Trinity College Dublin, Dublin, Ireland) at room temperature with field applied up to 1 Tesla.

\subsection{Preparation of Cobalt Ferrite Nanoparticles in Aqueous Phase}

The $\mathrm{CoFe}_{2} \mathrm{O}_{4}$ NPs were prepared based on the method reported by Biswal et al. [27] with some modifications. In a $250 \mathrm{~mL} \mathrm{RBF}$, cobalt nitrate $\left(\mathrm{Co}\left(\mathrm{NO}_{3}\right)_{2} \cdot 6 \mathrm{H}_{2} \mathrm{O}\right)(0.6 \mathrm{~g} / 0.002$ moles $)$ was dissolved in $100 \mathrm{~mL}$ degassed water. To this, iron(II) chloride ( $0.8 \mathrm{~g} / 0.004$ moles $)$ was added followed by the addition of ammonium hydroxide solution, until the cobalt-iron solution measured $\mathrm{pH}$ of 11 . This mixture was heated in an oil bath to $80^{\circ} \mathrm{C}$ and stirred for $1 \mathrm{~h}$. The solution was allowed to cool to room temperature and the product was collected by magnetic separation (1.2 Tesla). The product was washed with Millipore water several times until the $\mathrm{pH}$ of the nanoparticle solution was neutral. Then the water was removed by rotary evaporation followed by drying under vacuum using a Schlenk line. The nanoparticulate product was then analyzed using VSM, TEM and Raman techniques.

\subsection{Preparation of $\mathrm{CoFe}_{2} \mathrm{O}_{4} @ \mathrm{SiO}_{2}$ Core-Shell Nanoparticles}

The $\mathrm{SiO}_{2}$ coating was performed using the methods reported by Corr et al. [5] with some modifications.

In a $250 \mathrm{~mL}$ RBF, $25 \mathrm{~mL}$ of the citric acid stabilized NP solution $\left(0.028 \mathrm{~g}\right.$ of NPs $/ 1.19 \times 10^{-4}$ moles $)$ was mixed with $25 \mathrm{~mL}$ ammonium hydroxide in $100 \mathrm{~mL}$ of Ethanol. To this solution, TEOS solution $\left(400 \mu \mathrm{L} / 0.3732 \mathrm{~g} / 1.791 \times 10^{-3}\right.$ moles $)$ was added. The mixture was sonicated in ice for $1 \mathrm{~h}$. The resultant NPs were extracted again using magnetic separation and were washed several times with EtOH. They were then dried by rotary evaporation. They particles were then analyzed using VSM, TEM, Raman and XRD analysis techniques.

\subsection{Preparation of $\mathrm{CoFe}_{2} \mathrm{O}_{4} @ \mathrm{SiO}_{2} / \mathrm{TiO}_{2}$ Core-Shell Nanostructures}

The $\mathrm{TiO}_{2}$ coating was performed based the method in Pang et al. [32] with some modifications. $\mathrm{CoFe}_{2} \mathrm{O}_{4} @ \mathrm{SiO}_{2}(0.0495 \mathrm{~g})$ was dispersed by sonication in $100 \mathrm{~mL}$ EtOH. Titanium tetrabutoxide $\left(0.4 \mathrm{~mL} / 1.175 \times 10^{-3}\right.$ moles $)$ was added by syringe and the solution was sonicated for approximately $5 \mathrm{~min}$. After sonication the mixture was allowed to stir continuously at room temperature for $24 \mathrm{~h}$. The product was then extracted by magnetic separation and washed 3 times with EtOH to clean and the solvent was then removed by rotary evaporation and were analyzed with VSM, Raman, XRD, TEM and EDX analysis to show their composition.

Samples obtained from this procedure were then sintered at $600{ }^{\circ} \mathrm{C}$ to study their stability and to produce the catalytically active titania-anatase phase.

\subsection{Catalytic Activity Testing of $\mathrm{TiO}_{2}$ Coating}

Photo-catalytic testing was carried out on the samples containing a $\mathrm{TiO}_{2}$ shell based on the methods reported by Pang el al. [16]. $10 \mu \mathrm{L}$ of methylene blue solution $\left(1 \times 10^{-3}\right.$ moles $)$ was added to $3 \mathrm{~mL}$ of 
Millipore water in a quartz cuvette. To this, a few milligrams of nanoparticles were added to the solution and it was allowed to stir in darkness for $1 \mathrm{hr}$. After the hour, a UV-Vis spectrum was recorded for the sample at time $T_{0}$. The solution was then placed under a UV light at low wavelength and allowed to stir for $10 \mathrm{~min}$. Another UV-Vis spectrum was then recorded. The sample was then placed back under UV light for another ten minutes and this process was repeated every ten minutes for $1 \mathrm{~h}$. A background of Millipore water was ran before each scan. This entire process was repeated for each sample sintered at different temperatures.

\section{Conclusions}

We have demonstrated that magnetic cobalt ferrite nanoparticles can be prepared and coated by the double $\mathrm{SiO}_{2} / \mathrm{TiO}_{2}$ layer using metallorganic precursors to give new functional "core-shell" nano-structures. Although the $\mathrm{SiO}_{2}$ coating is relatively simple to obtain, the complete $\mathrm{TiO}_{2}$ coating on silica proves much more challenging to produce, most likely due to the mismatch between the structures of these two materials. The TEM, EDX, VSM and Raman spectroscopy results confirm the presence of the $\mathrm{TiO}_{2}$ layer, although the thickness of $\mathrm{TiO}_{2}$ coating is very thin. Despite the additional non-magnetic coatings result in a lower value of the magnetic moment, the particles can still be retrieved from the reaction mixture by simple magnetic separation.

We have demonstrated that the sintering of $\mathrm{CoFe}_{2} \mathrm{O}_{4} @ \mathrm{SiO}_{2} @ \mathrm{TiO}_{2}$ at $600{ }^{\circ} \mathrm{C}$ allows us to produce photocatalytically active anatase/rutile titania phases at the surface of these nanostructures enabling efficient photocatalytic oxidation of methylene blue under UV light. The retention of magnetism in these core-shell nanostructures is of particular importance allowing the magnetic recovery and re-use of the catalyst.

Further work is however necessary in this field in order to optimize the reaction conditions to improve the thickness and quality both the $\mathrm{SiO}_{2}$ and $\mathrm{TiO}_{2}$ coatings on the magnetic nanoparticles. Different reaction times may be considered along with different amounts of the $\mathrm{TiO}_{2}$ precursors used. Eventually these nanoparticles are expected to be used in photocatalysis and potentially in biomedical applications such as for example antibacterial control systems.

\section{Acknowledgments}

This work was supported by the EU-ITN network Mag(net)icFun (PITN-GA-2012-290248), the EU FP7 "FutureNanoNeeds" and the Ministry of Education and Science of the Russian Federation (Grant No. 14.B25.31.0002).

\section{Author Contributions}

DG and RS has performed all synthetic and experimental work and corresponding descriptions. JG assisted with the photocatalytic activity studies. DG and YG wrote and edited the manuscript.

\section{Conflicts of Interest}

The authors declare no conflict of interest. 


\section{References}

1. Wei, S.Y.; Wang, Q.; Zhu, J.H.; Sun, L.Y.; Lin, H.F.; Guo, Z.H. Multifunctional composite core-shell nanoparticles. Nanoscale 2011, 3, 4474-4502.

2. Chen, M.J.; Yang, W.T.; Yin, M.Z. Synthesis and applications of nanoparticles in biology. Prog. Chem. 2012, 24, 2403-2414.

3. Clime, L.; Le Drogoff, B.; Zhao, S.; Zhang, Z.; Veres, T. Magnetic nanocarriers: From material design to magnetic manipulation. Int. J. Nanotechnol. 2008, 5, 1268-1305.

4. Corr, S.A.; Rakovich, Y.P.; Gun'ko, Y.K. Multifunctional magnetic-fluorescent nanocomposites for biomedical applications. Nanoscale Res. Lett. 2008, 3, 87-104.

5. Corr, S.A.; Gun'ko, Y.K.; Douvalis, A.P.; Venkatesan, M.; Gunning, R.D.; Nellist, P.D. From nanocrystals to nanorods: New iron oxide-silica nanocomposites from metallorganic precursors. J. Phys. Chem. C 2008, 112, 1008-1018.

6. Solinas, S.; Piccaluga, G.; Morales, M.P.; Serna, C.J. Sol-gel formation of $\gamma-\mathrm{Fe}_{2} \mathrm{O}_{3} / \mathrm{SiO}_{2}$ nanocomposites. Acta Mater. 2001, 49, 2805-2811.

7. Kodama, H.; Momose, S.; Sugimoto, T.; Uzumaki, T.; Tanaka, A. Chemically synthesized fept nanoparticle material for ultrahigh-density recording. IEEE Trans. Magn. 2005, 41, 665-669.

8. Yi, D.K.; Selvan, S.T.; Lee, S.S.; Papaefthymiou, G.C.; Kundaliya, D.; Ying, J.Y. Silica-coated nanocomposites of magnetic nanoparticles and quantum dots. J. Am. Chem. Soc. 2005, 127, 4990-4991.

9. Zhang, M.; Cushing, B.L.; O'Connor, C.J. Synthesis and characterization of monodisperse ultra-thin silica-coated magnetic nanoparticles. Nanotechnology 2008, 19, doi:10.1088/0957-4484/19/8/085601.

10. Fu, Q.T.; He, T.T.; Yu, L.Q.; Liu, Y.J.; Chai, Y.M.; Liu, C.G. Preparation and application of silica microspheres with magnetic core/mesoporous silica shell. Prog. Chem. 2010, 22, 1116-1124.

11. Gleeson, O.; Davies, G.L.; Peschiulli, A.; Tekoriute, R.; Gun'ko, Y.K.; Connon, S.J. The immobilisation of chiral organocatalysts on magnetic nanoparticles: The support particle cannot always be considered inert. Org. Biomol. Chem. 2011, 9, 7929-7940.

12. Gleeson, O.; Tekoriute, R.; Gun'ko, Y.K.; Connon, S.J. The first magnetic nanoparticle-supported chiral dmap analogue: Highly enantioselective acylation and excellent recyclability. Chemistry 2009, 15, 5669-5673.

13. O’Dalaigh, C.; Corr, S.A.; Gun'ko, Y.; Connon, S.J. A magnetic-nanoparticle-supported 4-n,n-dialkylaminopyridine catalyst: Excellent reactivity combined with facile catalyst recovery and recyclability. Angew. Chem. Int. Edit. 2007, 46, 4329-4332.

14. Ansari, S.A.; Husain, Q. Potential applications of enzymes immobilized on/in nano materials: A review. Biotechnol. Adv. 2012, 30, 512-523.

15. Kneuer, C.; Sameti, M.; Haltner, E.G.; Schiestel, T.; Schirra, H.; Schmidt, H.; Lehr, C.-M. Silica nanoparticles modified with aminosilanes as carriers for plasmid DNA. Int. J. Pharm. 2000, 196, 257-261.

16. Pang, S.C.; Kho, S.Y.; Chin, S.F. Fabrication of magnetite/silica/titania core-shell nanoparticles. J. Nanomater. 2012, 2012, doi:10.1155/2012/427310.

17. Shi, Z.L.; Du, C.; Yao, S.H. Preparation and photocatalytic activity of cerium doped anatase titanium dioxide coated magnetite composite. J. Taiwan Inst. Chem. Eng. 2011, 42, 652-657. 
18. Fu, W.; Yang, H.; Li, M.; Li, M.; Yang, N.; Zou, G. Anatase $\mathrm{TiO}_{2}$ nanolayer coating on cobalt ferrite nanoparticles for magnetic photocatalyst. Mater. Lett. 2005, 59, 3530-3534.

19. Chen, X.; Mao, S.S. Titanium dioxide nanomaterials: Synthesis, properties, modifications, and applications. Chem. Rev. 2007, 107, 2891-2959.

20. Fujishima, A.; Zhang, X.; Tryk, D.A. TiO 2 photocatalysis and related surface phenomena. Surf. Sci. Rep. 2008, 63, 515-582.

21. Zhang, W.F.; He, Y.L.; Zhang, M.S.; Yin, Z.; Chen, Q. Raman scattering study on anatase $\mathrm{TiO}_{2}$ nanocrystals. J. Phys. D 2000, 33, doi:10.1088/0022-3727/33/8/305.

22. Diebold, U. The surface science of titanium dioxide. Surf. Sci. Rep. 2003, 48, 53-229.

23. $\mathrm{Li}, \mathrm{X} . Z$.; $\mathrm{Li}, \mathrm{F} . \mathrm{B}$. Study of $\mathrm{Au} / \mathrm{Au}^{3+}-\mathrm{TiO}_{2}$ photocatalysts toward visible photooxidation for water and wastewater treatment. Environ. Sci. Technol. 2001, 35, 2381-2387.

24. Peng, T.; Zhao, D.; Dai, K.; Shi, W.; Hirao, K. Synthesis of titanium dioxide nanoparticles with mesoporous anatase wall and high photocatalytic activity. J. Phys. Chem. B 2005, 109, 4947-4952.

25. Gong, X.-Q.; Selloni, A. Reactivity of anatase $\mathrm{TiO}_{2}$ nanoparticles: The role of the minority(001) surface. J. Phys. Chem. B 2005, 109, 19560-19562.

26. Lee, C.-T.; Lee, H.-Y.; Chen, H.-W. Gan mos device using $\mathrm{SiO}_{2}$ insulator grown by photoelectrochemical oxidation method. Electron Device Lett. 2003, 24, 54-56.

27. Biswal, D.; Peeples, B.N.; Peeples, C.; Pradhan, A.K. Tuning of magnetic properties in cobalt ferrite by varying $\mathrm{Fe}^{+2}$ and $\mathrm{Co}^{+2}$ molar ratios. J. Magn. Magn. Mater. 2013, 345, 1-6.

28. Baldi, G.; Bonacchi, D.; Innocenti, C.; Lorenzi, G.; Sangregorio, C. Cobalt ferrite nanoparticles: The control of the particle size and surface state and their effects on magnetic properties. J. Magn. Magn. Mater. 2007, 311, 10-16.

29. Hu, J.; Bando, Y.; Zhan, J.; Yuan, X.; Sekiguchi, T.; Golberg, D. Self-assembly of $\mathrm{SiO}_{2}$ nanowires and $\mathrm{Si}$ microwires into hierarchical heterostructures on a large scale. Adv. Mater. 2005, 17, 971-975.

30. Ohsaka, T.; Izumi, F.; Fujiki, Y. Raman spectrum of anatase, $\mathrm{TiO}_{2}$. J. Raman Spectrosc. 1978, 7, 321-324.

31. Zhang, J.; Li, M.; Feng, Z.; Chen, J.; Li, C. UV Raman spectroscopic study on $\mathrm{TiO}_{2}$. I. Phase transformation at the surface and in the bulk. J. Phys. Chem. B 2005, 110, 927-935.

32. Pang, S.C.; Kho, S.Y.; Chin, S.F. Fabrication of magnetite/silica/titania core-shell nanoparticles. J. Nanomater. 2012, 2012, 427310, doi:10.1155/2012/427310.

(C) 2014 by the authors; licensee MDPI, Basel, Switzerland. This article is an open access article distributed under the terms and conditions of the Creative Commons Attribution license (http://creativecommons.org/licenses/by/3.0/). 